\section{Can we prescribe TMP/SMX prophylaxis without any concerns equally for all patients with rheumatic disease?}

We read with great interest the recent article by Park et $a l^{1}$ and appreciate the authors' efforts to assess the benefit and safety of trimethoprim-sulfamethoxazole (TMP/SMX) as primary prophylaxis for pneumocystis pneumonia in patients with rheumatic diseases, exposed to prolonged high-dose glucocorticoids.

However, we would like to point out one concern in the incidence of adverse drug reactions related to TMP/SMX prophylaxis. Despite its efficacy, TMP/SMX could induce adverse events that could cause some patients to discontinue prophylaxis and increase the risk for Pneumocystis jirovecii pneumonia. There could be a disease gap for the development of adverse events, and higher risk was indicated in patients with systemic lupus erythematosus (SLE) compared with other rheumatic diseases. In patients with SLE, the reaction rate was estimated to be up to $27.3 \%-53 \% \%^{2-5}$ and anti-Ro/ SS-A antibody was especially warned to be a prognostic factor. ${ }^{2}$ In addition, a prophylactic regimen is also important to assess safety. This is because adverse events requiring discontinuation of TMP/ SMX prophylaxis were higher in patients with usual prophylaxis of a single-strength TMP/SMX tablet daily compared with graded administration. ${ }^{26}$ For these reasons, detailed description revealing safety profiles based on individual diseases and prophylactic regimens would be required.

In conclusion, we acknowledge the interesting results provided by the authors, confirming the safety and efficacy of TMP/SMX prophylaxis. However, we believe that evaluating safety in patients with SLE would guide the readers in having a better understanding regarding the TMP/SMX prophylaxis in patients with rheumatic diseases.

\section{Yasuhiro Suyama, ${ }^{1,2}$ Masato Okada ${ }^{2}$}

${ }^{1}$ Division of Rheumatology, JR Tokyo General Hospital, Tokyo, Japan 'Immuno-Rheumatology Center, St. Luke's International Hospital, St. Luke's International University, Tokyo, Japan
Correspondence to Dr Yasuhiro Suyama, Immuno-Rheumatology Center, St. Luke's International Hospital, St. Luke's International University, Tokyo, Japan; y-suyama@jreast.co.jp

Funding This research received no specific grant from any funding agency in the public, commercial or not-for-profit sectors.

Competing interests None declared.

Provenance and peer review Not commissioned; internally peer reviewed.

(c) Article author(s) (or their employer(s) unless otherwise stated in the text of the article) 2019. All rights reserved. No commercial use is permitted unless otherwise expressly granted.

\section{Check for updates}

To cite Suyama Y, Okada M. Ann Rheum Dis 2019;78:e17.

Received 16 January 2018

Accepted 18 January 2018

Published Online First 6 February 2018

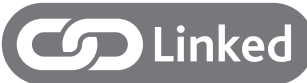

- http://dx.doi.org/10.1136/annrheumdis-2018-213045

Ann Rheum Dis 2019;78:e17. doi:10.1136/annrheumdis-2018-213027

\section{REFERENCES}

1 Park JW, Curtis JR, Moon J, et al. Prophylactic effect of trimethoprim-sulfamethoxazole for pneumocystis pneumonia in patients with rheumatic diseases exposed to prolonged high-dose glucocorticoids. Ann Rheum Dis 2018;77:644-9.

2 Suyama Y, Okada M, Rokutanda R, et al. Safety and efficacy of upfront graded administration of trimethoprim-sulfamethoxazole in systemic lupus erythematosus: a retrospective cohort study. Mod Rheumatol 2016;26:557-61.

3 Petri M, Allbritton J. Antibiotic allergy in systemic lupus erythematosus: a case-control study. J Rheumatol 1992;19:265-9.

4 Pope J, Jerome D, Fenlon $D$, et al. Frequency of adverse drug reactions in patients with systemic lupus erythematosus. J Rheumatol 2003;30:480-4.

5 Jeffries M, Bruner G, Glenn S, et al. Sulpha allergy in lupus patients: a clinical perspective. Lupus 2008;17:202-5.

6 Utsunomiya M, Dobashi H, Odani T, et al. Optimal regimens of sulfamethoxazoletrimethoprim for chemoprophylaxis of Pneumocystis pneumonia in patients with systemic rheumatic diseases: results from a non-blinded, randomized controlled trial. Arthritis Res Ther 2017;19:7. 